\title{
Alginate-chitosan Coated Lecithin Core Shell Nanoparticles for Curcumin: Effect of Surface Charge on Release Properties and Biological Activities
}

\author{
Lokesh Pathak ${ }^{1}$, Tripathy Amrutanand ${ }^{2}$, Yadvendra Agrawal' \\ ${ }^{1}$ Institute of Research and Development, Gujarat Forensics Sciences University, Gandhinagar, Gujarat, INDIA. \\ ${ }^{2}$ Al-Ameen College of Pharmacy, Hosur Road, Bangalore-560027, Karnataka, INDIA.
}

\begin{abstract}
Alginate-chitosan coated lecithin nanoparticles loaded with Curcumin have been prepared by layer deposition of alginate on lecithin/chitosan nanoparticles and were characterized. The prepared nanoparticles were physicochemically characterized to ensure alginate coating. The encapsulation efficiency and loading of the active nutraceutical were assessed using spectrophotometric measurements. The biological activities of the prepared nanoparticles were assessed by membrane stabilization effect of the nanoparticles on goat RBCs under hypotonic and thermally induced conditions. The biocompatibility of blank nanocarriers was assessed by performing In vitro cytotoxicity studies on HEK cell lines. The release profile of curcumin from alginate uncoated and alginate coated nanoparticles were compared to analyze effect of surface charge of the particles on studied bioactivities. It was found that uniformly sized alginate coated nanoparticles were formed with negative surface charge. It was also observed that there was no significant difference due to surface charge of the nanoparticles on cytotoxicity and membrane stabilization activity. However alginate coating offered more controlled release of the curcumin in acidic conditions suggesting that these alginate coating imparted enteric coating character.
\end{abstract}

Key words: Layer deposition, Membrane stabilization, MTT assay, Membrane stabilization, Biocompatibility.

\section{INTRODUCTION}

Nanotechnology has offered numerous benefits to the field of pharmaceuticals/ cosmeceuticals/nutraceutical industries. ${ }^{1-3}$ These benefits were availed whenever active ingredient were unable to exert intended action for treatment or prevention of the disease process, functional food, preservatives, gene delivery, improved topical adherence etc. Core shell nanoparticles has been active area of research within the domain of nanoformulations as it has offered great benefits especially in the drug delivery systems of pharmaceutical industry. Soppimath et al. have synthesized polymeric core shell nanoparticles for $\mathrm{pH}$ responsive delivery of the drug molecules. ${ }^{4}$ In an another study, Pacitaxel (anticancer drug) delivery was greatly enhanced when incorporated in lipid core shell nanoparticles stabilized by Pluronic F-127 polymer. ${ }^{5}$ Lipid core shell nanoparticles were found to be effective for controlling the release of proteins like Vascular Endothelial Growth Factor (VEGF) and lysozyme. ${ }^{6}$ The core shell nanoparticles also present opportunity of surface modification for targeted delivery of potent anticancer drugs therefore reducing chances of chemotherapy induced toxicity. ${ }^{7}$ Hence further exploring the possibilities of formation of novel core-shell nanoparticles and their applications present an exciting opportunity in novel drug delivery platform of nutraceuticals.
Submission Date: 30-08-2016; Revision Date: 17-11-2016; Accepted Date: 23-11-2016

DOI: 10.5530/ijper.51.2.32 Correspondence: Mr. Lokesh P Pathak, Institute of Research and Development Gujarat Forensics Sciences University Gandhinagar, Gujarat, INDIA.

Phone no: +91-79-23977137; Fax : +91-79-23247465 / 23256251

E-mail: mee.lokesh@gmail. com

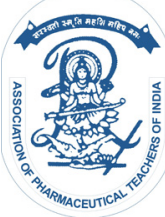

www.ijper.org 
Curcumin, bioactive agent present in yellow spice Turmeric and commonly used as culinary Ingredient in South Asia is non-toxic and pluripotent molecule being investigated for intervention in inflammation. ${ }^{8}$ carcinogenesis, diabetes ${ }^{9}$ and other ailments. However, its use as marketed formulation has been restrained due to its low aqueous solubility and hence bioavailability. For improving this pharmacokinetic properties various nanocarriers have been evaluated. e.g. curcumin was loaded in lactoferrin nanoparticles for alleviating neurotoxicity, ${ }^{10}$ curcumin nano-phospholipid dispersion for improved bioavailability, ${ }^{11}$ curcumin loaded solid lipid nanoparticles for treatment in arthritis, ${ }^{12}$ solid lipid nanoparticles loaded with curcumin for anti-inflammatory activities, ${ }^{13}$ mixed emulsion of curcumin for improving bioaccessibility, ${ }^{14}$ etc. Although the preparation of various core shell nanoparticles and encapsulation of curcumin in different nanoformulations has been studied extensively, there are very few researches directed toward exploration of effect of curcumin upon its encapsulation in core shell nanoparticles especially lipid core shell nanoparticles. In previous studies we have presented encapsulation of curcumin in self assembled lipid core shell nanoparticles for functional food applications. ${ }^{15}$ However the mentioned nanoparticles possessed chitosan coating imparting positive surface charge to the nanoparticles. It was learnt that these nanoparticles owing to their chitosan coating were prone to degradation in acidic environment. ${ }^{16}$ It was also inferred that chitosan would lose its mucoadhesive property at an acidic $\mathrm{pH}$ in the stomach, therefore losing its important physicochemical properties. To circumvent this important problem we decided to tune the surface charge of the lecithin core shell nanoparticles by acid resistant biodegradable biopolymer sodium alginate.

In this article we present preparation of curcumin loaded lipid core shell nanoparticles coated by primary chitosan and secondary sodium alginate layer availing sequential electrostatic interactions between lipid/polymer and then polymer/polymer which allowed tuning the surface charge on nanoparticles from positive to negative. The system was characterized physicochemically and was subjected to in-vitro membrane stabilization studies as an anti-inflammatory bioassay. The impact of surface charge of similarly sized nanoparticles on cytotoxicity of Human Embryonic Kidney Cell Lines (HEK) was assessed. Photostability enhancement of curcumin by both types of lipid core shell nanoparticles were performed subjecting these nanoparticles to ultraviolet radiation of sufficient intensity. The results obtained confirm that these type of lipid core shell nanoparticles present an oppprtunity to manipulate surface charge, release profile, cytotoxicity and environmental stability and could be availed for encapsulation of hydrophobic small organic molecules having pharmacokinetic issues, environmental instability, etc.

\section{MATERIALS AND METHODS}

Soya Lecithin (Lipoid S45) was a kind gift from Lipoid GmBH, Gemany. Chitosan (DA 85\%, MW: $150 \mathrm{kDa}$ ) was obtained from Central Institute of Fisheries Technology, Cochin Kerala, India; Sodium alginate was procured from Sisco Research laboratories, Andheri, Mumbai, India. Goat RBCs were prepared from heparinised blood obtained from veterinary approved local slaughterhouse. All other chemical and reagents used in the bioassays were procured from Fluka and Sigma AAldrich, USA and were used as received without further purification.

\section{Preparation of loaded and unloaded lecithin/ chitosan nanoparticles and alginate coated lecithin chitosan nanoparticles}

Blank and curcumin loaded lecithin/chitosan nanoparticles were prepared by procedure described by Sonvico et al. ${ }^{17}$ Briefly soya lecithin was dissolved in ethanol to constitute organic phase whereas chitosan solution of prescribed concentration constituted aqueous phase. The organic phase was slowly injected with syringe with sharp needle into stirring aqueous phase to form self assembled lecithin chitosan nanoparticles. For formation of curcumin loaded chitosan nanoparticles, varied concentrations of curcumin were added in the organic phase along with lecithin.

Alginate coated lecithin/chitosan nanoparticles (ALGLCN) were prepared by the slight modifications in the met hod described by Bagre et al. and Lie et al..$^{18-19}$ Briefly $10 \mathrm{mg} / \mathrm{ml}$ concentration sodium alginate stock solution was prepared. The curcumin loaded and blank lecithin/ chitosan nanoparticles after preparation were subjected to ultracentrifugation at $5000 \mathrm{rpm}$ speed (REMI, India) for $4 \mathrm{~h}$. The centrifugation at this controlled speed allowed formation of LCN concentrated suspension layer near bottom of centrifuge tubes and clearer solution at the top. The clear supernatant was discarded and concentrated LCN were added dropwise to the previously diluted solution of sodium alginate. The mixture was allowed to stir for $1 \mathrm{~h}$. in order to complete coating process of sodium alginate. After $30 \mathrm{~min}$, the solution was subjected to ultracentrifugation $(15,000 \mathrm{rpm}$; REMI India) to form pellets of the ALG-LCNs. For formation of curcumin loaded ALG-LCNs, concentrate of curcumin loaded LCN was added to sodium alginate solution. The optimization of the ALG-LCNs was 
performed varying the concentration of sodium alginate and assessing its hydrodynamic diameter, surface charge inversion, encapsulation efficiency and curcumin loading.

\section{Size and particle size distribution}

Size of the prepared nanoparticles was assessed by measuring hydrodynamic diameter of the nanoparticles in suspension by dynamic light scattering technique using Malvern instrument (Zetasizer ZS nano, UK). The laser wavelength of $633 \mathrm{~nm}$ was used and all measurements were carried out in triplicate and sizes were expressed in $\mathrm{nm} \pm \mathrm{SD}$. Particle size distributions were expressed in the form of polydispersity index (PDI).

\section{Surface charge (Zeta potential)}

Surface charge on the nanoparticles were measured by measuring electrophoretic mobility of the nanoparticles under applied electric field. The analysis was performed using Zetasizer nano ZS instrument (Malvern UK) and results were expressed in millivolts \pm SD.

\section{Morphology}

Morphology of the prepared nanoparticles was assessed by Scanning electron microscopy (SEM) technique. For SEM analysis the samples were prepared by spin coating of the samples on the grapheme sheet. The samples were silver sputtered to increase sensitivity of electron microscopy.

\section{Encapsulation efficiency (EE) and Curcumin loading (CL)}

The Encapsulation efficiency and curcumin loading were measured using spectrophotometric techniques using JASCOv600 UV spectrophotometer. The $\lambda \max$ of the curcumin in the concentration range of $1-10 \mathrm{ppm}$ concentrations were observed at $421 \mathrm{~nm}$ with squared correlation efficient of 0.994 . The particles pellets of the nanoparticles obtained were allowed to disintegrate in absolute ethanol and suitably diluted to record its concentration by intrapolation from the caliberation curve. The EE and CL were calculated using the following formulae.

$$
\begin{aligned}
& \mathrm{EE}(\%)=\frac{\mathrm{W}_{\text {total }} \square\left(\mathrm{W}_{\text {free }}+\mathrm{W}_{\text {precipitated }}\right)}{\mathrm{W}_{\text {total }}} \square 100 \\
& \mathrm{CL}(\%)=\frac{\mathrm{W}_{\text {total }} \square\left(\mathrm{W}_{\text {free }}+\mathrm{W}_{\text {precipitated }}\right)}{\mathrm{W}_{\text {np }}} \square 100
\end{aligned}
$$

Whereas Wtotal represents total amount of curcumin added for preparing loaded nanoparticles, Wfree is amount of curcumin found in supernatant after centrifugation, Wnp represents the weight of nanoparticles after gravimetric analysis.

\section{Thermal characterization (Differential Scanning Calorimetry)}

The thermal property of the samples were studied in the powder form by recording the differential scanning colorimeter (DSC) response curve in the temperature range $30^{\circ} \mathrm{C}$ to $300{ }^{\circ} \mathrm{C}$, at a heating rate of $20^{\circ} \mathrm{C} / \mathrm{min}$, in nitrogen atmosphere using SHIMADZU differential scanning calorimeter (DSC-60). The analysis was performed in TA-60WS software package.

\section{Powder X-ray diffraction studies}

Phillip Analytical PW1710 X-ray diffractrometer was used to study the diffraction pattern. The spectra were recorded using $\mathrm{Cu} \mathrm{K} \alpha$ at the voltage of $40 \mathrm{KV}$, a current of $20 \mathrm{~mA}$, a time constant of 4 , a channel width of $7 \mathrm{~mm}$ and chart speed of $10 \mathrm{~mm} / \mathrm{min}$.

\section{Fourier Transform Infrared spectroscopy (FT-IR)}

FT-IR analysis of RP and RLNs were performed on FT-IR spectrometer (JASCO, 4100, Japan) with diffused reflectance technique (DR-41 sample cell).

\section{Cell line culture and maintenance:}

HEK cells (Human Embryonic Kidney) cells were purchased from NCCS, Pune, India. Cells were maintained in Dulbecco's modified Eagle's medium (DMEM, Sigma,USA) containing $10 \%$ heat-inactivated fetal bovine serum (FBS, Lonza), $100 \mathrm{U} / \mathrm{ml}$ penicillin, 100 $\mathrm{U} / \mathrm{ml}$ streptomycin and $2 \mathrm{mM} \mathrm{L}$-glutamine at $37^{\circ} \mathrm{C}$ in a humidified atmosphere of $5 \%$ CO2. Cells were passaged every 2-3 days to maintain exponential growth.

\section{The cell viability assay}

The cell viability of the samples was studied by means of a colorimetric microculture assay (MTT) on HEK cell lines ${ }^{20} .1 \times 104$ cells/well were seeded in $100 \mu \mathrm{l}$ DMEM, supplemented with 10\% FBS in each well of 96-well microculture plates and incubated for $24 \mathrm{~h}$ at $37^{\circ} \mathrm{C}$ in a $\mathrm{CO}_{2}$ incubator. The desired concentrations of the samples were made and added to the wells with respective vehicle control. After $24 \mathrm{~h}$ of incubation, $10 \mu \mathrm{l}$ MTT (3-(4, 5-dimethylthiazol-2-yl)-2, 5-diphenyl tetrazolium bromide) $(5 \mathrm{mg} / \mathrm{ml})$ was added to each well and the plates were further incubated for $4 \mathrm{~h}$. Then the supernatant from each well was carefully removed, formazan crystals were dissolved in $100 \mu \mathrm{l}$ of DMSO and absorbance at $540 \mathrm{~nm}$ wavelength was recorded. Dose response curves were constructed between the range $200 \mu \mathrm{M}-1 \mu \mathrm{M}$ for samples under study. The $\%$ cell viability was expressed i.e. decreasing number of viable cells with increasing concentration of samples. The difference in cell viability between blank LCN, 
blank ALG-LCN and respective curcumin loaded samples in these nanoparticles were studied and compared. All measurements were carried out in triplicate and results were compared by employing ANOVA test at confidence interval of $95 \%$.

\section{In vitro release profile of the curcumin from LCNs and ALG-LCNs}

In vitro release study was performed in acidic solution $0.1 \mathrm{~N} \mathrm{HCl}(\mathrm{pH} 1.2)$ and at $\mathrm{pH} 6.8$ phosphate buffer by some modifications in the dialysis bag method as described by Shah et al. ${ }^{21}$ Dialysis membrane of 12,00014,000 molecular weight cut-off (Fisher brand) was used for the experiment. Glycerine in the membrane was washed with the warm Milli-Q water thrice and five $\mathrm{ml}$ of LCNs and ALG-LCNs (5mg) were suspended in dissolution medium.

Temperature was maintained at $37^{\circ} \mathrm{C}$ during the experiment at stirring speed of $100 \mathrm{rpm}$. Two milliliters aliquot were withdrawn at predetermined time intervals and replaced by an equal volume of a fresh dissolution medium. After suitable dilution, the samples were analyzed spectrophotometrically at $421 \mathrm{~nm}$ for amount of curcumin released. The concentrations of the curcumin were analysed by calculating its concentrations from calibration curve. Tween $80(1 \% \mathrm{w} / \mathrm{v})$ was used as dissolution medium to facilitate dissolution of curcumin in the dissolution medium.

\section{Photostability Studies of Curcumin in LCNs and ALG-LCNs}

The UV protective effect of LCNs and ALG-LCNs on Curcumin was studied by adopting and modifying the method described by $\mathrm{Li}$ et al.22 Briefly Uncoated lecithin nanoparticles, LCNs, ALG-LCNs suspensions with curcumin (each sample having $5 \mathrm{mg}$ of curcumin) and equivalent amount of free curcumin (in 10\% ethanol) were taken in a small vials and were exposed to UV light source placed at a distance of $15 \mathrm{~cm}$ over a period of 24 hours. Volume equivalent to $100 \mu \mathrm{g}$ was taken out from each vial and then diluted in $10 \mathrm{ml}$ after 24 hours and analysed for amount of curcumin present at the end of 24 hour in the sample.

\section{Thermal stability Studies of Curcumin in LCNs and ALG-LCNs}

The thermal stability studies of the prepared nanoparticles were carried out by procedure described as follows. Briefly, ALG-LCNs and LCNs and free curcumin $(1 \%$ tween 80$)$ were added in glass vials and were incu- bated at $63^{\circ} \mathrm{C}$ for $30 \mathrm{~min}$ and $100^{\circ} \mathrm{C}$ for 10 minutes to simulate pasteurization process. The vials were taken out and equilibrated with room temperature for about an hour and their physicochemical parameters like size, PDI, surface charge were assessed. The $0.1 \mathrm{ml}$ of each sample solution was taken out and were passed through $0.45 \mu \mathrm{m}$ ultra filter with a syringe and recoveries of the curcumin were calculated by recording its absorbance at $421 \mathrm{~nm}$. The higher recoveries meant greater absorbance of the curcumin in the respective samples.

\section{The In-vitro anti-inflammatory assays}

\section{The membrane stabilization assay on GRBC}

The membrane stabilization assays were performed to investigate whether there was any compromise in antiinflamamtory activity of curcumin when encapsulated in prepared nanocarriers. The method adopted was slight modification in the method previously reported. ${ }^{23}$ Briefly, fresh Goat blood was collected from a local slaughter house in a heparinized tube with added preservatives. The collected blood was immediately centrifuged at cold temperature and erythrocytes were washed with isotonic phosphate buffer saline (PBS). The Erythrocytes were resuspended in buffer solution at $\mathrm{pH} 7.4$ to obtain fixed concentration of RBCs. This sample was considered as control sample. The curcumin loaded in nanocarriers and free curcumin at equivalent concentration of $100 \mu \mathrm{g}$ was added to eppendorf tubes containing RBCs to make final volume of solution to $2 \mathrm{ml}$. The mixture and RBCs were incubated at body temperature for $30 \mathrm{~min}$. After this, tubes were kept in ice bath and centrifuged at $5000 \mathrm{rpm}$ speed. The concentration of haemoglobin in the supernatant was measured by UV spectrophotometer at a fixed wavelength of $540 \mathrm{~nm}$. For membrane stabilisation under thermal conditions, all the parameters and concentrations were maintained same except that samples under studies were kept at $60^{\circ} \mathrm{C}$ for 30 minutes except at room temperature. The experiments were performed in triplicate and analysed by one way ANOVA statistical technique.

\section{Statistics Tests}

Data are shown as means \pm standard deviations in the measurement $(\mathrm{SD})(\mathrm{n}=3)$. Statistical data were analyzed by one way ANOVA test at the significance level of $\mathrm{P}=0.05,0.1$ and 0.01 performing Turkey post test to compare all groups using GraphPad Prism 5 software. 


\section{RESULTS}

\section{Size, Surface charge and size uniformity of the nanoparticles}

In previous studies, it was observed that upto $5 \mathrm{mg}$ of curcumin could be loaded in lipid/biopolymer nanoparticles with satisfactory values for size, positive surface charge and particle size distribution ${ }^{15}$. Hence $5 \mathrm{mg}$ of curcumin was loaded in self assembled nanoparticles for further sodium alginate coating. The concentrate of curcumin loaded LCNs were taken after centrifugation and were added to $20 \mathrm{ml}$ of suitably diluted sodium alginate solution in the concentration of $0.01,0.025$, $0.050,0.075$ and $0.1 \% \mathrm{w} / \mathrm{v}$. The results obtained are expressed in Table 1. It was observed that submicrometer range alginate coated nanoparticles could be formed when alginate concentration was upto $0.075 \%$ $\mathrm{w} / \mathrm{v}$. However at the concentration of $0.1 \%$ particles were aggregated rapidly in the solution. The inversion in surface charge above $20 \mathrm{mV}$ was observed at concentration of $0.025 \% \mathrm{w} / \mathrm{v}$ and above, however there was no significant difference in the values of surface charge at concentration of 0.050 and $0.075 \% \mathrm{w} / \mathrm{v}$ suggesting saturation of interacting amino groups of positively charged chitosan with negative charged carboxylate groups of alginate. The optimum size, surface charge and uniformity values for the particles were observed at the concentration of $0.05 \% \mathrm{w} / \mathrm{v}$ of sodium alginate. Hence batch with this concentration was selected for further studies. In addition purpose of the research was also to investigate effect of alginate uncoated and alginate coated Particles on cytotoxicity of the cells as well a membrane stabilization effect. For this type of comparison we also prepared LCNs with similar hydrodynamic diameter to that of ALG-LCNs.

\section{Morphology}

Morphology assessment by SEM experiments have been depicted in Figure 1. It was observed that ALGLCNs of $<300 \mathrm{~nm}$ size of roughly spherical shape were formed. The spherical shape of nanopaticle was highly beneficial with respect to cellular internalization of the nanoparticles as suggested by Jo et al. ${ }^{24}$

\section{Encapsulation efficiency (EE) and Curcumin loading}

For the formation of ALG-LCNs only ratio of sodium alginate was varied to chitosan and drug remained constant. However preparation of concentrates of curcumin loaded LCNs and process of alginate coating has contributed to significant change in encapsulation efficiencies and curcumin loading of the prepared samples. The data of EE and CL are represented in Table 1. It was observed that curcumin was lost upto $5-10 \%$ during alginate coating process and formation of concentrates.

\section{FT-IR spectroscopy}

FT-IR spectroscopy of sodium alginate, physical mixture of curcumin powder-chitosan-alginate-lecithin and curcumin loaded ALG-LCNs have revealed important information regarding possible interactions between functional groups of added ingredients in formulation and are presented in Figure 2. It has also helped to gain insight into possible mechanism of coating of alginate on the nanoparticles. Alginate has presented peaks at wavenumbers (expressed in $\mathrm{cm}^{-}{ }^{-1}$ ) of $3423(\mathrm{OH}$ stretching vibrations), 2921 (stretching vibration of alkyl group), 1649 (keto group stretching vibrations), 1620 (assymetric carboxylate anion stretching), 1419 (symmetric carboxylate anion stretching), 1093 (CH-OH in cyclic alcohol) and 1029 (C-O-C stretching). Curcumin physical mixture has shown predominant peaks of curcumin at 3510 (phenolic OH stretch), 3010 (aromatic CH stretch), 1735 (stretching frequency of keto group) etc. However in Curcumin loaded ALG-LCNs prominent peaks of Curcumin were either disappeared or reduced in intensity suggesting complete encapsulation of curcumin inside lecithin core. There was a substantial reduction in asymmetric and symmetric carboxylate anion frequencies of sodium alginate suggesting their involvement in ionic bond formation with amino group of chitosan.

\section{Thermal studies}

DSC thermograms of alginate, physical mixture of all ingredients and curcumin loaded ALG-LCNs have been represented in Figure 3. DSC thermogrtam of alginate has represented endothermic peak $84^{\circ} \mathrm{C}$ with a onset at $40^{\circ} \mathrm{C}$ and exothermic peak at $257{ }^{\circ} \mathrm{C}$ representing decomposition of the biopolymer at suggested by Soares et al. ${ }^{25}$ On comparing the thrmograms of physical mixture of nanocomponents and curcumin loaded ALG-LCNs it was observed that thermogram patterns were completely changed upon encapsulation of curcumin. Also curcumin peaks in physical mixtures at $197^{\circ} \mathrm{C}$ with a onset of $185^{\circ} \mathrm{C}$ were completely disappeared in nanoparticles system. There was reduction in the noises in peaks due to several nanocomponents in nanoparticulate system as compared to its physical mixture suggesting almost all components interacted mutually to form thermally co-existing unit.

\section{Crystallinity}

Crystallinity of the nanoformulations has great role to play in solubility and therefore release profile of the 


\begin{tabular}{|c|c|c|c|c|c|c|}
\hline $\begin{array}{l}\text { Sr. } \\
\text { No. }\end{array}$ & $\begin{array}{l}\text { Alginate } \% \\
\text { (w/w) }\end{array}$ & $\begin{array}{c}\text { EE (\% } \% \\
\text { s.d.) }\end{array}$ & CL (\%₫s.d.) & $\begin{array}{c}\mathrm{Z} \text { average size (nm } \\
\pm \text { s.d.) }\end{array}$ & $\begin{array}{l}\text { Polydispersity } \\
\text { Index }\end{array}$ & $\begin{array}{c}\text { Zeta Potential (mV } \\
\pm \text { s.d.) }\end{array}$ \\
\hline 1 & 0.01 & $80 \pm 1.23$ & $1.23 \pm 0.02$ & $175.0 \pm 1.55$ & $0.275 \pm 0.022$ & $20.2 \pm 1.50$ \\
\hline 2 & 0.025 & $77 \pm 0.89$ & $0.65 \pm 0.6$ & $118.2 \pm 0.63$ & $0.321 \pm 0.003$ & $-21 \pm 0.25$ \\
\hline 3 & 0.050 & $80 \pm 0.98$ & $0.78 \pm 0.34$ & 311.9 & 0.395 & $-42.80 \pm 0.06$ \\
\hline 4 & 0.075 & $72 \pm 0.90$ & $0.83 \pm 0.33$ & $611.11 \pm 1.45$ & 0.450 & $-41.23 \pm 0.02$ \\
\hline 5 & 0.1 & ND & ND & ND & ND & ND \\
\hline
\end{tabular}

active ingredient. ${ }^{26} \mathrm{XRD}$ studies have revealed that crystallinity of the curcumin nanoformulations has been completely diminished as there were no intense peaks in XRD of loaded ALG-LCNs as shown in Figure 4. On the contrary, physical mixtures of the nanocomponents have shown distinct and intense peaks at theta angles of $7.22^{\circ}, 8.76^{\circ}, 10.6^{\circ}, 17.99^{\circ}, 19.52^{\circ}, 34.25^{\circ}$ etc. It has been observed that there was increase in systemic bioavailability of antifungal drug itraconazole when it was incorporated in amorphous nanoparticulate form ${ }^{27}$. Hence, this novel amorphous nanoparticulate system ought to enhance the solubility and other pharmacokinetic properties of curcumin encapsulated in it.

\section{In-vitro drug release profile}

In-vitro release profile of the curcumin in its powdered form, in LCNs and ALG-LCNs have shown distinct profiles. The release profile of curcumin in LCNs and ALG-LCNs differed significantly at initial acidic $\mathrm{pH}$ ( $\mathrm{pH}$ 1.2). Curcumin has shown burst release from LCNs whereas controlled release was observed from ALG-LCNs at acidic pH in initial 2 hours. At pH 6.8 upto $80 \%$ of curcumin released from LCNs whereas in ALG-LCNs upto $80 \%$ of curcumin was released at the end of 12 hours suggesting sustained release profile. This could be attributed to property of chitosan layer

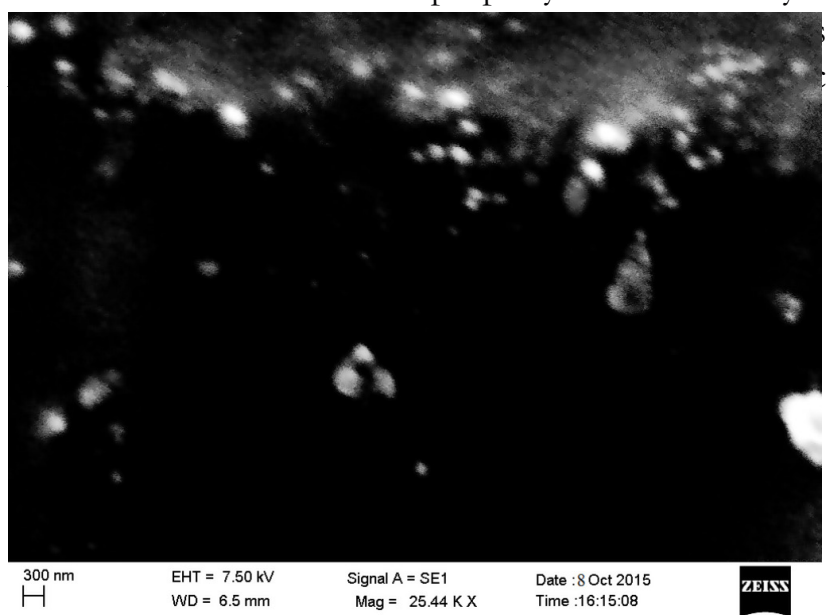

Figure 1: Scanning Electron Microscopy of Alginate coated lecithin/chitosan nanoparticles. lecithin to the outer aqueous environment. In case of ALG-LCNs ionization of amino groups gets prevented hence preventing lecithin core from such exposure. Hence it could be concluded that alginate coating offers enteric coating to LCNs preventing their damage and mucoadhesive properties. The release profile of piperine from different formulations have been depicted in Figure 5.

\section{Cytotoxicity assay}

It was reported that surface charge of the nanoparticles plays an important role in cellular internalization as well cellular toxicity. ${ }^{28}$ The preparation of lipid core nanoparticles with opposite surface charges prompted us to observe their effect on cellular toxicity. Hence toxicity studies of unloaded nanocarriers were performed on Human embryonic Kidney cells by MT'T assay. HEK cells were selected for these studies because previously these cells have been used to study cellular toxicity of the nanoparticles. ${ }^{29}$ For assessing the effect of surface charge of the nanoparticles on cellular toxicity it was essential to maintain all other variables constant including size of the nanoparticles. For this, Chitosan coated lecithin nanoparticles were prepared taking different ratios of lecithin and chitosan so that their sizes would match to that of ALG-LCNs. It was observed that there was no significant differences in cell viability of HEK cells after 24 hours (Figure 6). This could be attributed to the fact that thin layer of alginate could not make a significant difference in interaction with cellular membranes of HEK cells and size played an important role in determining cytotoxicity as compared to surface charge of the nanoparticles.

\section{In-vitro- anti-inflammatory activities}

It was observed that there was significant difference in membrane stabilization effect of curcumin when loaded in LCNs and ALG-LCNs. Curcumin loaded in LCNs has offered greater membrane stabilization activity as compared to in ALG-LCNs. This could be attributed to greater adherence of positively charged $\mathrm{LCNs}$ to membrane of the GRBCs and protect lysis of the RBCs. 

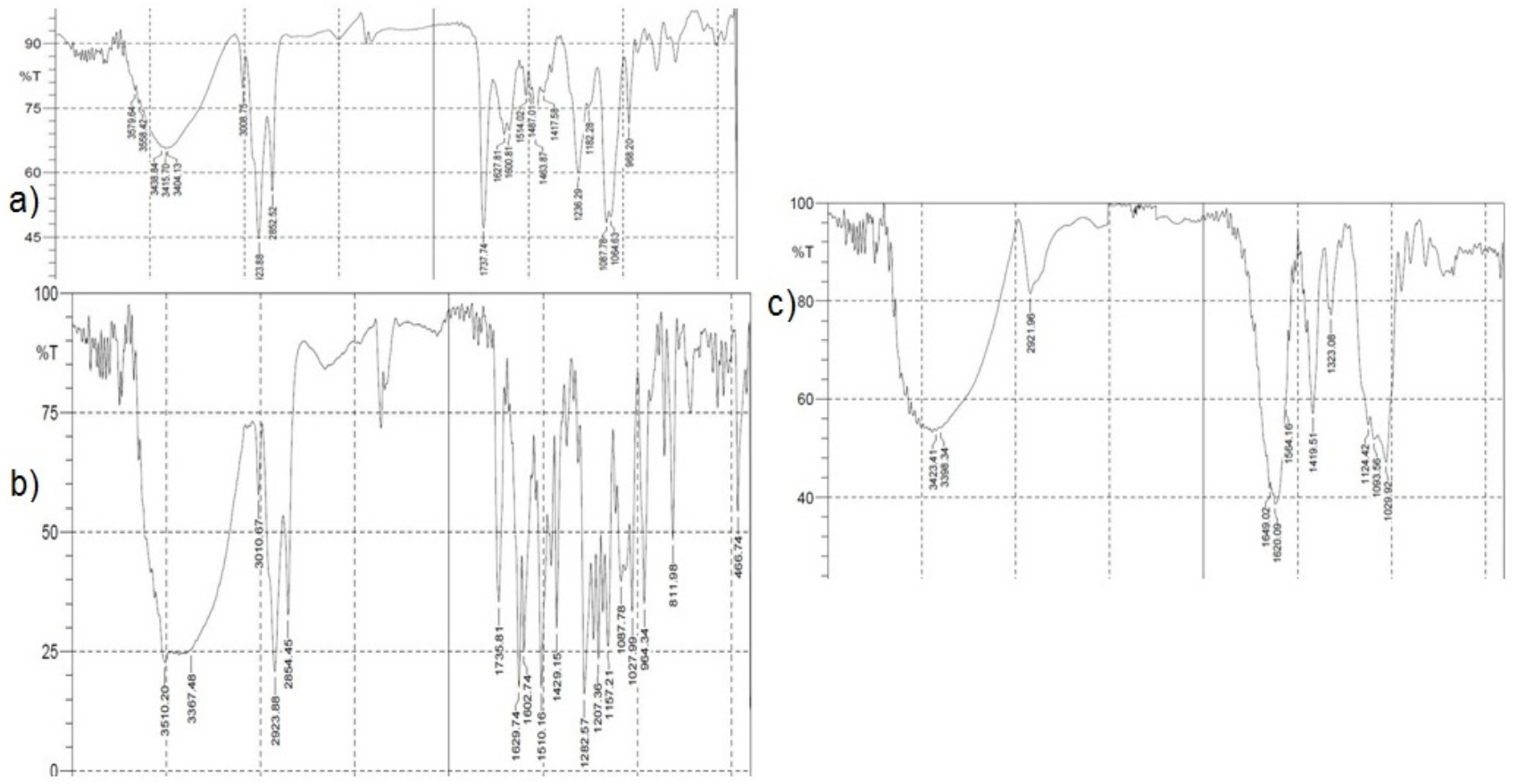

Figure 2: FT-IR spectroscopy of a) Curcumin loaded nanoparticles b) Physical mixture of the components of the nanoparticles c) alginate polymer.

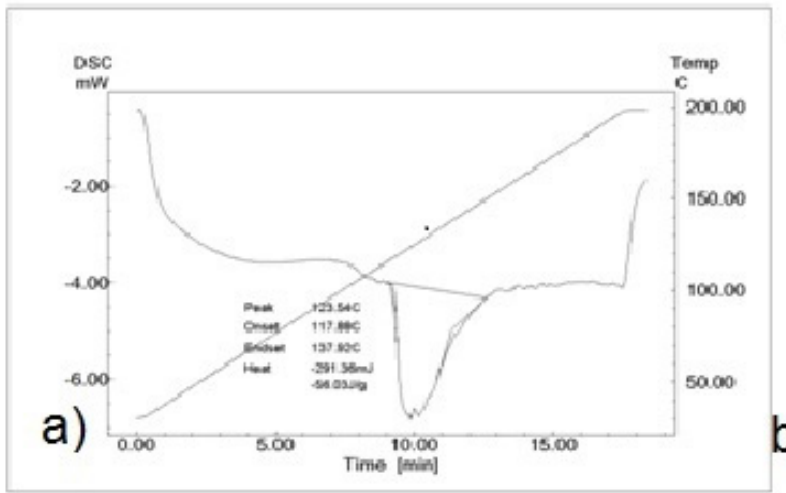

b)
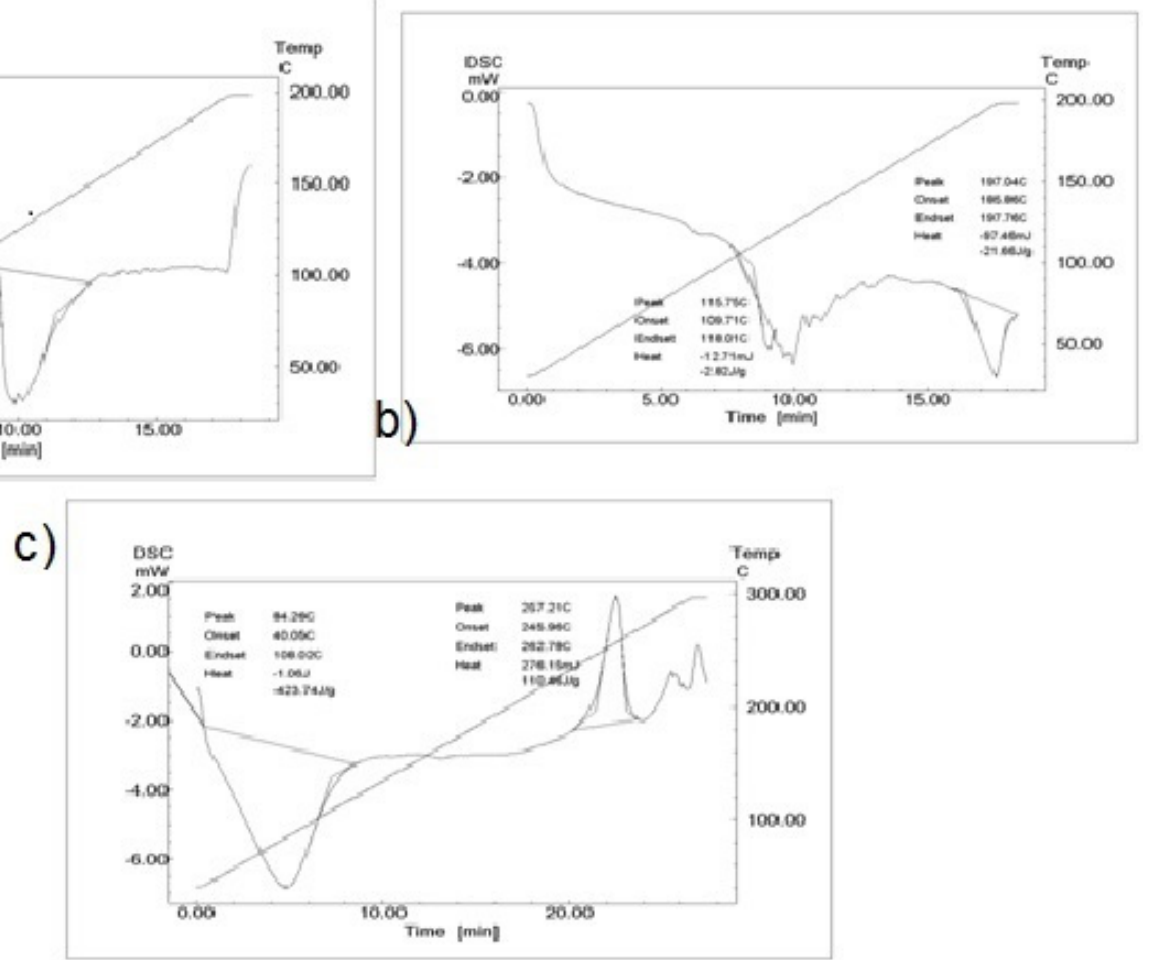

Figure 3: DSC of a) Curcumin loaded nanoparticles b) Physical mixture of the nanoparticles components c) alginate.

However in thermally induced haemolysis both types of nanoparticles prevented haemolysis to equal extent. This could be due to thermal energy induced loosening of chitosan-RBC membrane interaction. The data have been presented in Figure 7.

\section{Photoprotective effect of ALG-LCNs and LCNs on} curcumin

It was observed that curcumin in both the formulations was protected to equal extent as compared to in the dissolved form in methanol. This signifies that there 
a)
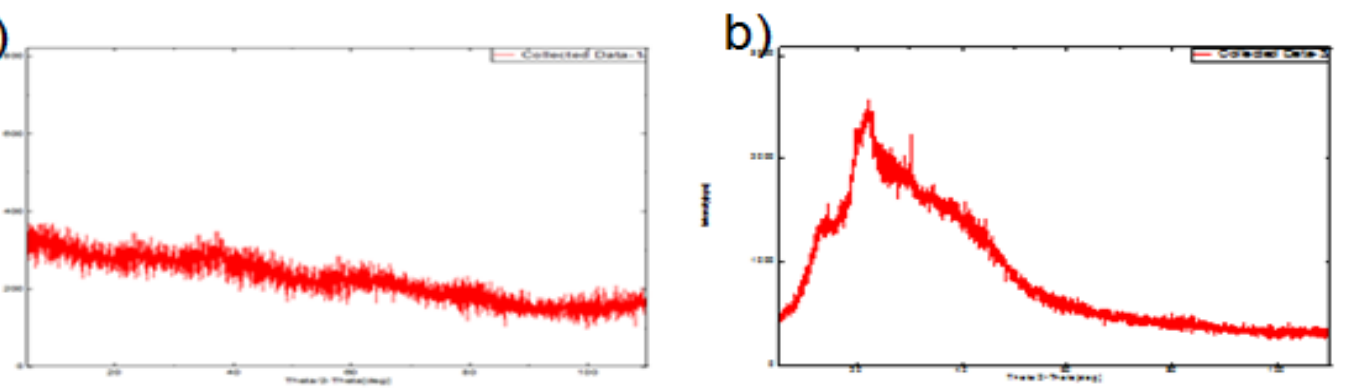

c)

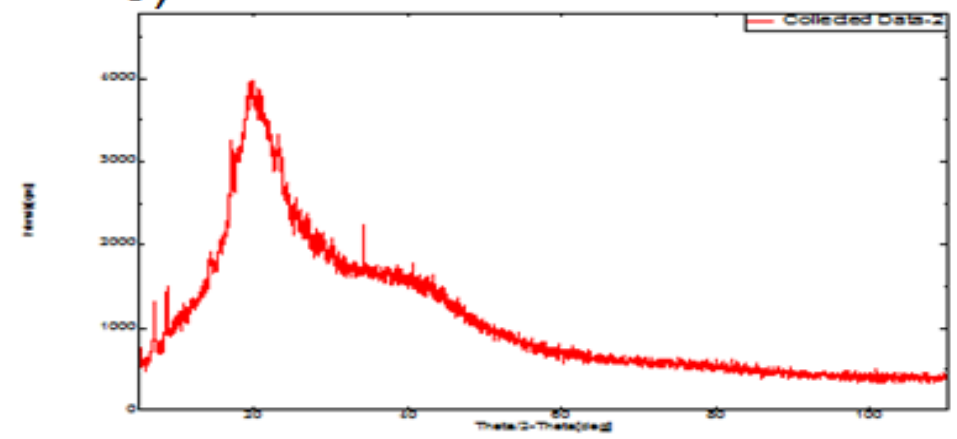

Figure 4: Powder X-ray diffraction study of a) Alginate coated nanoparticles b) alginate c) physical mixture of the formulation components.

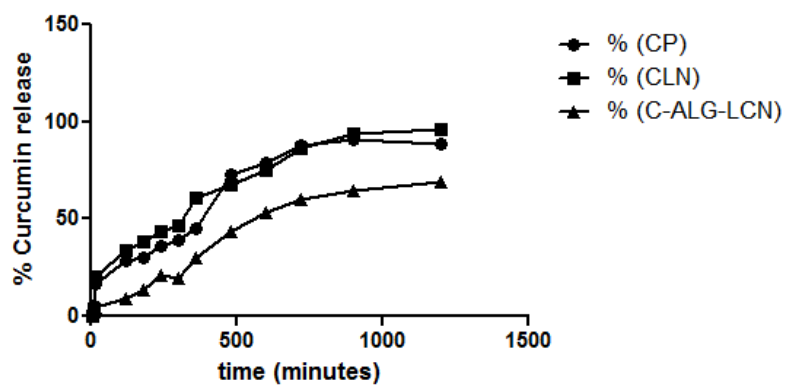

Figure 5: In-vitro release profiles of the curcumin from different lecithin core shell nanoparticles.

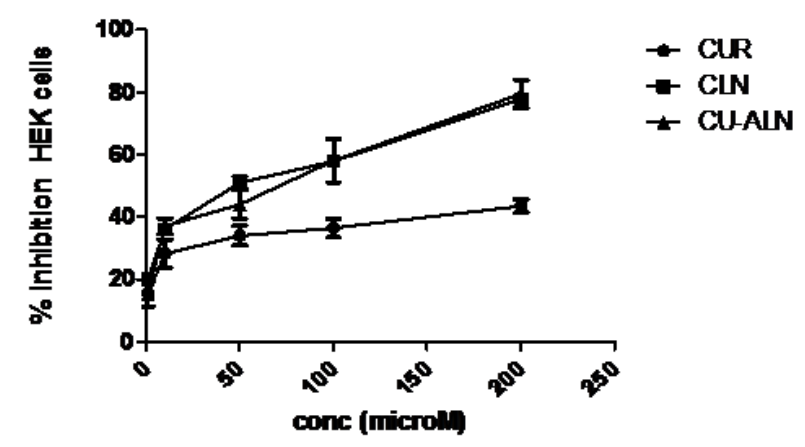

Figure 6: Cell viability studies of Curcumin from different formulation on Human embryonic kidney cells.

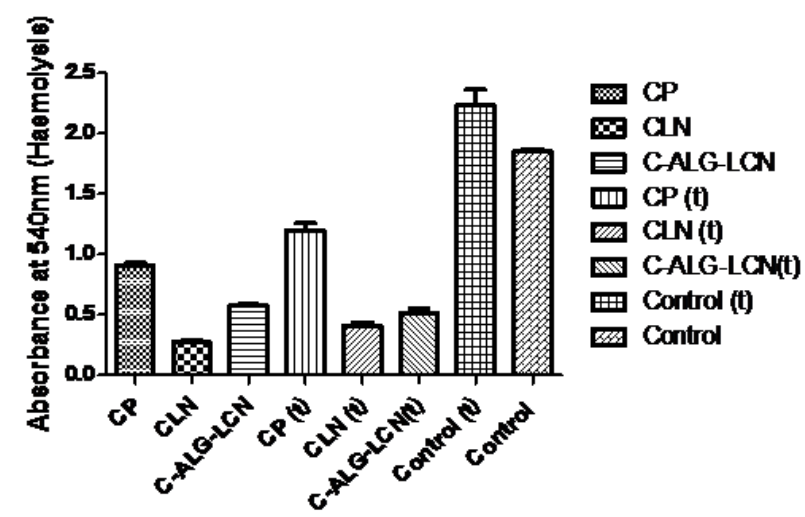

Figure 7: Comparison of membrane stabilisation of goat RBCs by curcumin in different formulations.

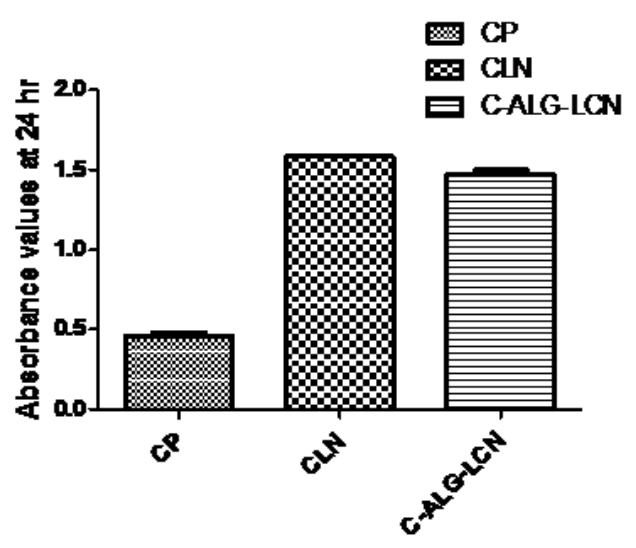

Figure 8: Photostability of the curcumin loaded in surfactant solution, chitosan coated and alginate coated lecithin core shell nanoparticles. 


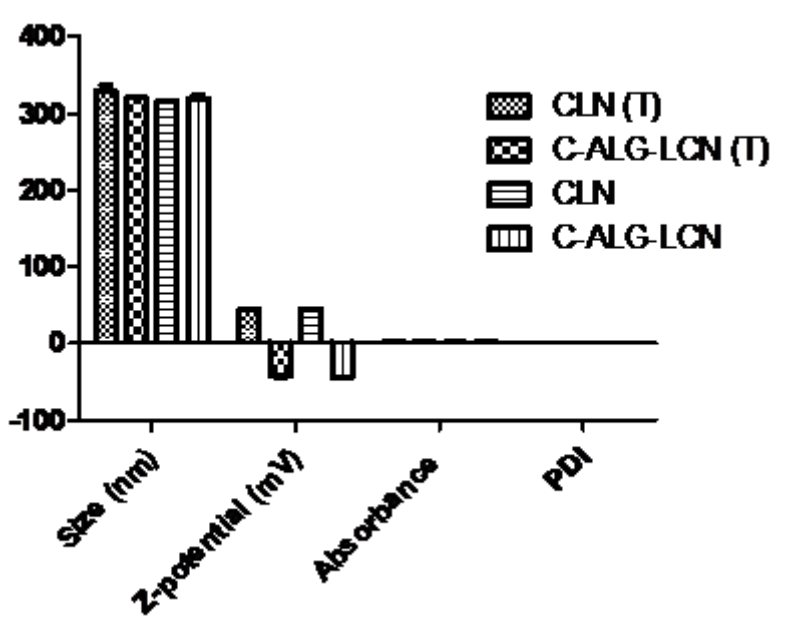

Figure 9: The comparison of thermal stabilities of curcumin loaded in two nanosystems.

was no special or additional effect of alginate coating on photoprotection of curcumin. The results have been presented in the Figure 8.

\section{Thermal stability of curcumin in LCNs and ALG-LCNs}

It was observed that curcumin was more stable in the ALG-LCNs as compared to LCNs. There was more curcumin in the solution after incubation at higher temperature. There was significantly higher quantity of curcumin found in LCNs nanoparticles $(\mathrm{P}>0.005)$. This could be attributed to extra layer of strongly bound supramolecular assembly of alginate to chitosan. The absorbances of curcumin in both the nanoparticulate systems have been represented in Figure 9.

\section{CONCLUSION}

Lecithin/chitosan nanoparticles offered opportunity to coat their cationic surface by anionic biopolymer like alginate which was thought to be imparting additional beneficial properties in bioactivities, stability and release properties. However, our observation have revealed that although in-vitro cell viability of the HEK cells were not affected by this change, the release properties got significantly changed in alginate coated nanoparticles. Release studies have shown that novel ALG-LCNs have imparted controlled and sustained release profile to curcumin active ingredient. Hence tuning of the surface charge of lipid biopolymers present exciting prospects for scientists working in nutraceutical and pharmaceutical industries.

\section{ACKNOWLEDGEMENT}

Authors would like to thank Dr. Abhinav Kanwal for carrying out cytotoxicity studies on HEK cells.

\section{CONFLICT OF INTEREST}

Authors state no conflict of interest

\section{ABBREVIATIONS USED}

SEM: Scanning electron microscopy; DSC: Differential Scanning Calorimetry; FT-IR: Fourier Transform Infra Red; HEK: Human Embryonic Kidney; GRBC: Goat Red blood cells.

\section{REFERENCES}

1. Sozer N, Kokini JL. Nanotechnology and its applications in the food sector. Trends in biotechnology. 2009;27(2):82-9. https://doi.org/10.1016/j. tibtech.2008.10.010 PMid:19135747.

2. $\mathrm{Mu} \mathrm{L}$, Sprando RL. Application of nanotechnology in cosmetics. Pharmaceutical research. 2010;27:1746-9. https://doi.org/10.1007/s11095010-0139-1 PMid:20407919.

3. Liu YM, Chen H, Zeng FD. The Advance in Application of Nanotechnology in Pharmacy Research. Chinese Journal of Clinical Pharmacology. 2001;17(5):367-70.

4. Soppimath KS, Tan DW, Yang YY. pH-Triggered Thermally Responsive Polymer Core-Shell Nanoparticles for Drug Delivery. Advanced materials. 2005;17(3):318-23. https://doi.org/10.1002/adma.200401057.

5. Chan JM, Zhang L, Yuet KP, Liao G, Rhee JW, Langer R et al. PLGA-lecithinPEG core-shell nanoparticles for controlled drug delivery. Biomaterials. 2009;30(8):1627-34. https://doi.org/10.1016/j.biomaterials.2008.12.013 PMid:19111339.

6. Oh KS, Han SK, Lee HS, Koo HM, Kim RS, Lee KE, Han SS, Cho SH, Yuk SH. Core/shell nanoparticles with lecithin lipid cores for protein delivery. Biomacromolecules. 2006;7(8):2362-7. https://doi.org/10.1021/bm060362k PMid:16903683.

7. Liu H, Chen D, Li L, Liu T, Tan L, Wu X, et al. Multifunctional gold nanoshells on silica nanorattles: a platform for the combination of photothermal therapy and chemotherapy with low systemic toxicity. Angewandte Chemie. 2011;123(4):921-5. https://doi.org/10.1002/ange.201002820.

8. Weisberg SP, Leibel R, Tortoriello DV. Dietary curcumin significantly improves obesity-associated inflammation and diabetes in mouse models of diabesity. Endocrinology. 2008;149(7):3549-58. https://doi.org/10.1210/en.2008-0262 PMid:18403477 PMCid:PMC2453081.

9. Rao CV, Rivenson A, Simi B, Reddy BS. Chemoprevention of colon carcinogenesis by dietary curcumin, a naturally occurring plant phenolic compound. Cancer research. 1995; 55(2):259-66. PMid:7812955.

10. Bollimpelli VS, Kumar P, Kumari S, Kondapi AK. Neuroprotective effect of curcumin-loaded lactoferrin nano particles against rotenone induced neurotoxicity. Neurochemistry international. 2016; 95:37-45. https://doi. org/10.1016/j.neuint.2016.01.006 PMid:26826319.

11. Zou L, Zheng B, Zhang R, Zhang Z, Liu W, Liu C, et al. Enhancing the bioaccessibility of hydrophobic bioactive agents using mixed colloidal dispersions: Curcumin-loaded zein nanoparticles plus digestible lipid nanoparticles. Food Research International. 2016; 81:74-82. https://doi. org/10.1016/j.foodres.2015.12.035.

12. Arora R, Kuhad A, Kaur IP, Chopra K. Curcumin loaded solid lipid nanoparticles ameliorate adjuvant-induced arthritis in rats. European Journal of Pain. 2015;19(7):940-52. https://doi.org/10.1002/ejp.620 PMid:25400173.

13. Wang J, Wang H, Zhu R, Liu Q, Fei J, Wang S. Anti-inflammatory activity of curcumin-loaded solid lipid nanoparticles in IL-1 $\beta$ transgenic mice subjected to the lipopolysaccharide-induced sepsis. Biomaterials. 2015;53:475-83. https://doi.org/10.1016/j.biomaterials.2015.02.116 PMid:25890744. 
14. Zou L, Zheng B, Liu W, Liu C, Xiao H, McClements DJ. Enhancing nutraceutical bioavailability using excipient emulsions: Influence of lipid droplet size on solubility and bioaccessibility of powdered curcumin. Journal of functional foods. 2015;15:72-83. https://doi.org/10.1016/j.jf.2015.02.044.

15. Pathak L, Kanwal A, Agrawal Y. Curcumin loaded self assembled lipidbiopolymer nanoparticles for functional food applications. Journal of food science and technology. 2015; 52(10):6143-56. https://doi.org/10.1007/ s13197-015-1742-2 PMid:26396362 PMCid:PMC4573133.

16. Makhlof A, Tozuka Y, Takeuchi H. Design and evaluation of novel $\mathrm{pH}$-sensitive chitosan nanoparticles for oral insulin delivery. European journal of pharmaceutical sciences. 2011;42(5):445-51. https://doi.org/10.1016/j. ejps.2010.12.007 PMid:21182939.

17. Bagre AP, Jain K, Jain NK. Alginate coated chitosan core shell nanoparticles for oral delivery of enoxaparin: in vitro and in vivo assessment. International journal of pharmaceutics. 2013;456(1):31-40. https://doi.org/10.1016/j. ijpharm.2013.08.037 PMid:23994363.

18. Li X, Kong $X$, Shi S, Zheng $X$, Guo G, Wei $Y$ et al. Preparation of alginate coated chitosan microparticles for vaccine delivery. BMC biotechnology. 2008;8(1):89. https://doi.org/10.1186/1472-6750-8-89 PMid:19019229 PMCid:PMC2603011.

19. Guan R, Kang T, Lu F, Zhang Z, Shen H, Liu M. Cytotoxicity, oxidative stress, and genotoxicity in human hepatocyte and embryonic kidney cells exposed to $\mathrm{ZnO}$ nanoparticles. Nanoscale research letters. 2012;7(1):1-7. https://doi. org/10.1186/1556-276X-7-602 PMid:23110934 PMCid:PMC3563552.

20. Shah M, Agrawal YK, Garala K, Ramkishan A. Solid lipid nanoparticles of a water soluble drug, ciprofloxacin hydrochloride. Indian journal of pharmaceutical sciences. 2012;74(5):434. https://doi.org/10.4103/0250474X.108419 PMid:23716872 PMCid:PMC3660870.
21. Li J, Shin GH, Lee IW, Chen X, Park HJ. Soluble starch formulated nanocomposite increases water solubility and stability of curcumin. Food Hydrocolloids. 2016;56:41-9. https://doi.org/10.1016/j.foodhyd.2015.11.024.

22. Muniyappan N, Nagarajan NS. Green synthesis of silver nanoparticles with Dalbergia spinosa leaves and their applications in biological and catalytic activities. Process Biochemistry. 2014;49(6):1054-61. https://doi. org/10.1016/j.procbio.2014.03.015.

23. Jo DH, Kim JH, Lee TG, Kim JH. Size, surface charge, and shape determine therapeutic effects of nanoparticles on brain and retinal diseases. Nanomedicine: Nanotechnology, Biology and Medicine. 2015;11(7):1603-11. https://doi.org/10.1016/j.nano.2015.04.015 PMid:25989200.

24. Soares JP, Santos JE, Chierice GO, Cavalheiro ET. Thermal behavior of alginic acid and its sodium salt. Eclética Química. 2004;29(2):57-64. https:// doi.org/10.1590/S0100-46702004000200009.

25. Leuner C, Dressman J. Improving drug solubility for oral delivery using solid dispersions. European journal of Pharmaceutics and Biopharmaceutics. 2000;50(1):47-60. https://doi.org/10.1016/S0939-6411(00)00076-X.

26. Jung JY, Yoo SD, Lee SH, Kim KH, Yoon DS, Lee KH. Enhanced solubility and dissolution rate of itraconazole by a solid dispersion technique. International journal of pharmaceutics. 1999;187(2):209-18. https://doi.org/10.1016/ S0378-5173(99)00191-X.

27. Fröhlich $\mathrm{E}$. The role of surface charge in cellular uptake and cytotoxicity of medical nanoparticles. Int J Nanomedicine. 2012;7(1):5577-91. https://doi. org/10.2147/IJN.S36111 PMid:23144561 PMCid:PMC3493258.

28. Selvaraj V, Bodapati S, Murray E, Rice KM, Winston N, Shokuhfar T et al. Cytotoxicity and genotoxicity caused by yttrium oxide nanoparticles in HEK293 cells. Int J Nanomedicine 2014;9:1379-91. https://doi.org/10.2147/ IJN.S52625 PMid:24648735 PMCid:PMC3958544.

\section{PICTORIAL ABSTRACT}

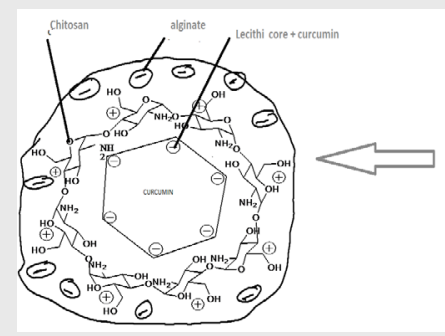

Step 1

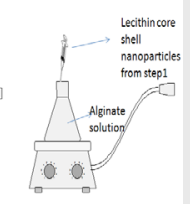

Step 2

\section{SUMMARY}

- In the present investigation, novel lipid core shell nanoparticles for encapsulation of dietary spice ingredient Curcumin were synthesized.

- The designed nanoparticles were stabilized with double coating of biodegradable biopolymers like chitosan and sodium alginate.

- It was found that prepared nanoparticles were successful in retaining anti-inflammatory activity of the curcumin as well have imparted sustained release profile to the curcumin.

\section{About Authors}

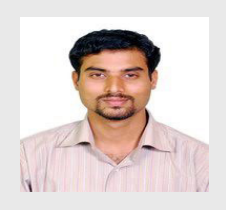

Mr. Lokesh P. Pathak: He is working as research scholar at Institute of research and development, affiliated to Gujarat Forensics sciences university, Gandhinagar, Gujarat. His research area is development of novel nutraceuticals as therapeutic agents. He is working under the guidance of Prof. Y.K. Agrawal, Director, Institute of research and development.

Cite this article: Pathak L, Amrutanand TS, Agrawal Y. Alginate-chitosan Coated Lecithin Core Shell Nanoparticles for Curcumin: Effect of Surface Charge on Release Properties and Biological Activities. Indian J of Pharmaceutical Education and Research. 2017;51(2):270-9. 